\title{
Catalytic $\mathbf{C}\left(\mathrm{sp}^{3}\right)-\mathrm{H}$ bond activation in tertiary alkylamines
}

Jesus Rodrigalvarez, Manuel Nappi, Hiroki Azuma, Nils J. Flodén, Matthew E. Burns and Matthew J. Gaunt* Department of Chemistry, University of Cambridge, Lensfield Road, Cambridge, United Kingdom. CB2 1EW

The development of robust catalytic methods to assemble tertiary alkylamines provides a continual challenge to chemical synthesis. In this regard, transformation of a traditionally unreactive $\mathrm{C}-\mathrm{H}$ bond, proximal to the nitrogen-atom, into a versatile chemical entity would be a powerful strategy for introducing functional complexity to tertiary alkylamines. A practical and selective metal-catalyzed $\mathrm{C}\left(\mathrm{sp}^{3}\right)-\mathrm{H}$ activation facilitated by the tertiary alkylamine functionality, however, remains an unsolved problem. Here, we report a Pd(II)-catalyzed protocol that appends arene feedstocks to tertiary alkylamines via $\mathrm{C}\left(\mathrm{sp}^{3}\right)-\mathrm{H}$ functionalization. A simple ligand for $\mathrm{Pd}(\mathrm{II})$ orchestrates the $\mathrm{C}-\mathrm{H}$ activation step in favor of deleterious pathways. The reaction can utilize both simple and complex starting materials to produce a range of multi-faceted $\gamma$-aryl tertiary alkylamines and can be rendered enantioselective. The enabling features of this transformation should be attractive to practitioners of synthetic and medicinal chemistry as well as other areas that utilize biologically-active alkylamines.

The development of transition metal-catalyzed methods for converting $\mathrm{C}\left(\mathrm{sp}^{3}\right)-\mathrm{H}$ bonds into new chemical functionality is an emerging technology that has the potential to streamline chemical synthesis ${ }^{15-17}$. An important feature of many $\mathrm{C}\left(\mathrm{sp}^{3}\right)-\mathrm{H}$ functionalization strategies is the use of coordinating groups, which locate a metal catalyst in proximity to a particular $\mathrm{C}-\mathrm{H}$ bond, thereby enabling reactivity and ensuring selectivity. In an ideal situation, a native functionality present in the molecule would be capable of steering the $\mathrm{C}\left(\mathrm{sp}^{3}\right)-\mathrm{H}$ activation via cyclometallation. Among a limited number of examples, carboxylic acids ${ }^{18,19}$ as well as primary and secondary amines ${ }^{20}$ have been most successfully deployed in combination with $\mathrm{Pd}(\mathrm{II})$-catalysts to affect $\mathrm{C}\left(\mathrm{sp}^{3}\right)-\mathrm{H}$ functionalization reactions. However, it is more common the native functional group needs to be modified with an additional directing auxiliary to modulate its coordinating ability, which has led to a diverse range of $\mathrm{Pd}(\mathrm{II})$-catalyzed $\mathrm{C}\left(\mathrm{sp}^{3}\right)-\mathrm{H}$ activation process ${ }^{21,22}$. Despite the efficacy of auxiliary-augmented $\mathrm{C}\left(\mathrm{sp}^{3}\right)-\mathrm{H}$ activation strategies, a number of practical drawbacks of this approach exist. Firstly, the auxiliary must be incorporated into the substrate prior to, and removed after, the $\mathrm{C}-\mathrm{H}$ transformation. Secondly, their removal sometimes requires harsh conditions that can be incompatible with delicate molecular architecture. A third, and arguably the most compelling, limitation is that auxiliary-augmented $\mathrm{C}\left(\mathrm{sp}^{3}\right)-\mathrm{H}$ activation is not possible if there is no functionality in the substrate to which a directing motif can be appended. This problem is 
especially pertinent when considering $\mathrm{C}\left(\mathrm{sp}^{3}\right)-\mathrm{H}$ activation in tertiary alkylamines; there is no simple way to attach and remove a directing auxiliary within a tertiary alkylamine motif ${ }^{23-30}$.

With an estimated $26 \%$ of all drugs and agrochemicals featuring a tertiary alkylamine ${ }^{1,2}$, the development of robust catalytic methods to assemble and modify the structure of these important molecular features provides a continual challenge to chemical synthesis ${ }^{3-12}$. A selective single-step transformation of a traditionally unreactive $\mathrm{C}-\mathrm{H}$ bond, proximal to the nitrogen atom, into a versatile chemical entity would be a particularly powerful strategy for introducing functional complexity to tertiary alkylamines. Despite the apparent efficacy of this ideal, practical and selective metalcatalyzed $\mathrm{C}\left(\mathrm{sp}^{3}\right)-\mathrm{H}$ activation facilitated by tertiary alkylamine scaffolds remains an elusive transformation (Figure 1a). A possible reason for this methodological deficiency is the ease with which the electron-rich nitrogen atom in tertiary alkylamines can undergo decomposition reactions in the presence of many transition metal salts and commonly used oxidants, in favor of the desired $\mathrm{C}-\mathrm{H}$ activation pathway (Figure $1 \mathrm{~b})^{13}$. Using alternative strategies, Hartwig has reported steric-controlled $\mathrm{Rh}^{31}, \mathrm{Ru}^{32}$ and Ir-catalyzed ${ }^{33} \mathrm{C}\left(\mathrm{sp}^{3}\right)-\mathrm{H}$ borylation at methyl groups within simple tertiary alkylamines, in some cases with selectivity at the $\beta$-position. Remote $\mathrm{C}\left(\mathrm{sp}^{3}\right)-\mathrm{H}$ oxidations using $\mathrm{Pt}^{34}, \mathrm{Ru}^{35} \mathrm{Fe}^{36}$ and $\mathrm{W}^{37}$ catalysts under strongly acidic conditions, wherein the transformation is guided by the $\mathrm{C}-\mathrm{H}$ bond reactivity rather than directing effect of the amine, have also been described. However, no examples of tertiary alkylamine-directed catalytic $\mathrm{C}\left(\mathrm{sp}^{3}\right)-\mathrm{H}$ functionalization have been reported (Figure 1a-b). Given the ubiquity of tertiary alkylamines in biologicallyimportant molecules and the potential efficacy of a method which introduces aryl entities proximal to the nitrogen motif $^{14}$, the development of tertiary alkylamine-directed catalytic $\mathrm{C}\left(\mathrm{sp}^{3}\right)-\mathrm{H}$ activation strategies to guide building block functionalization, fragment coupling and late-stage functionalization of biologically-relevant molecules is an unmet synthetic need (Figure 1c). 
a

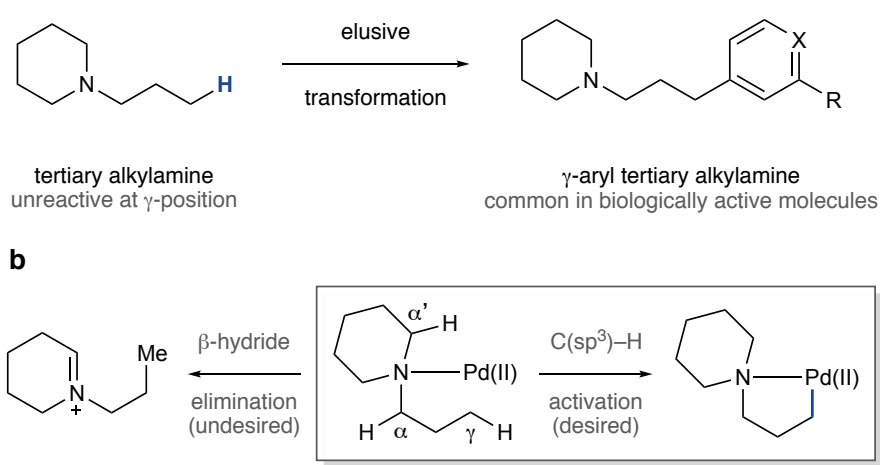

c
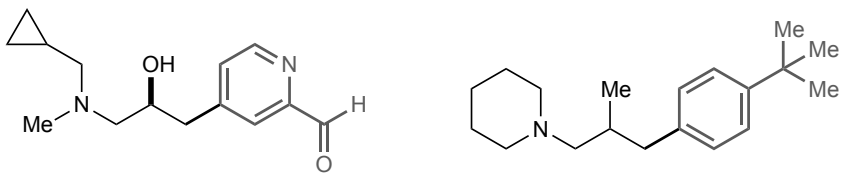

building block functionalization (e.g. library generation) convergent target synthesis

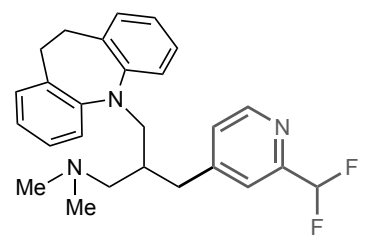<smiles>CCOC(=O)c1cccc(CC(C)CN(C)C)c1</smiles>

late-stage functionalization (e.g. trimipramine)

enantioselective $\mathrm{C}\left(\mathrm{sp}^{3}\right)-\mathrm{H}$ activation (to $\beta$-methyl, $\gamma$-(hetero)aryl propylamines)

Figure 1. Design plan towards $\gamma-\mathbf{C}\left(\mathbf{s p}^{3}\right)-\mathbf{H}$ arylation of tertiary alkylamines. a. Direct methods to selectively arylate tertiary alkylamines at the $\gamma$-position do not exist. b. Directed $\mathrm{C}\left(\mathrm{sp}^{3}\right)-\mathrm{H}$ activation is a potential solution to the functionalization of tertiary alkylamines, however, the presence of $\mathrm{C}-\mathrm{H}$ bonds adjacent to the nitrogen atom could lead to undesired $\beta$-hydride elimination. c. Applications for a $\mathrm{Pd}(\mathrm{II})$-catalyzed $\gamma-\mathrm{C}\left(\mathrm{sp}^{3}\right)-\mathrm{H}$ arylation of tertiary alkylamines, which include the functionalizing available tertiary alkylamine building blocks, a convergent strategy for target synthesis, late-stage functionalization, and enantioselective synthesis of tertiary alkylamines.

\section{Result and discussion}

We reasoned that a successful $\mathrm{Pd}(\mathrm{II})$-catalyzed tertiary alkylamine-directed $\mathrm{C}\left(\mathrm{sp}^{3}\right)-\mathrm{H}$ arylation strategy would be dependent on the effective coordination of the substrate to the metal. The nitrogen atom is nucleophilic but often sterically hindered, however, based on Ryabov's cyclopalladation studies with benzylamines ${ }^{38}$, we proposed that the opposing steric and electronic characteristics inherent to tertiary alkylamines might synergistically combine to promote formation of the mono-amine $\mathrm{Pd}(\mathrm{II})$ complex required for $\mathrm{C}-\mathrm{H}$ activation (Figure 1b). However, the $\mathrm{Pd}(\mathrm{II})$-ligated nitrogen motif in tertiary alkylamines will often be surrounded by a number of $\mathrm{C}-\mathrm{H}$ bonds that can undergo deleterious $\beta$-hydride elimination reactions. Initial investigations revealed that a reaction between amine 1a and phenylboronic acid 2a under commonly used Pd(II)-catalysis conditions led to significant amine decomposition and no arylation ${ }^{20}$. 
Computational analysis revealed a lower energy pathway for an acetate-assisted $\beta$-hydride elimination (Ts2) (Figure 2a) than the desired $\mathrm{C}\left(\mathrm{sp}^{3}\right)-\mathrm{H}$ activation (Ts1), supporting the experimental observations. Interestingly, inner-sphere acetate-assisted $\beta$-hydride elimination (Ts2) is rarely considered for this common decomposition reaction ${ }^{39}$, yet all of our calculations converged on this pathway. We considered whether the introduction of a ligand would modulate the energetic preference for these competing pathways. While a number of directing functional groups are capable of intrinsically switching between neutral and anionic coordination to the Pd(II)-catalyst, thereby supporting the use of ligands with diverse binding modes $^{40}$, the neutral coordinating nitrogen atom in tertiary alkylamines restricts the type of ligand that can be deployed for $\mathrm{C}\left(\mathrm{sp}^{3}\right)-\mathrm{H}$ activation. We speculated that $\mathrm{C}\left(\mathrm{sp}^{3}\right)-\mathrm{H}$ activation in tertiary alkylamines would be matched to the coordination properties of $N$-acetyl $\alpha$-amino acid ligands ${ }^{41-43}$, permitting the $\mathrm{Pd}(\mathrm{II})$-center to accommodate the bis-anionic ligand (which contains the basic acetamide needed for $\mathrm{C}-\mathrm{H}$ bond cleavage), the neutral amine and the vacant coordination site required for $\mathrm{C}-\mathrm{H}$ activation. $\mathrm{Yu}$ and co-workers have previously developed a $\mathrm{Pd}(\mathrm{II})$-catalyzed method for arylation of $\mathrm{C}\left(\mathrm{sp}^{3}\right)-\mathrm{H}$ bonds in $\mathrm{N}$-alkyl sulfonamides with aryl boronic acid derivatives. In their studies, they reported that an $\mathrm{N}$-acetyl amino acid ligand was crucial for reactivity, with no reaction in its absence. Interestingly, we found that including $N$-acetyl tert-leucine $\mathbf{4 a}$ as a ligand lowered the energy of $\mathrm{C}\left(\mathrm{sp}^{3}\right)-\mathrm{H}$ activation step (Ts3) relative to the corresponding ligand-assisted $\beta$-hydride elimination. We believe that the ligand distorts the co-planar geometry empirically required for $\beta$-hydride elimination (Ts4), making base-assisted $\mathrm{C}-\mathrm{H}$ activation the more favored pathway (see Supplementary Table 5) and represents an extension to the reactivity-inducing capacity of this class of ligand. Our calculations were validated by a reaction employing $25 \mathrm{~mol} \%$ of ligand $\mathbf{4 a}$, which produced a moderate yield of the $\gamma$-aryl alkylamine 3a. An extensive assessment of reaction parameters revealed optimal conditions which involved treatment of 2.5 equivalents of amine $1 \mathrm{a}$ and phenylboronic acid $\mathbf{2 a}$ with $10 \mathrm{~mol} \% \mathrm{Pd}(\mathrm{OAc})_{2}, 25 \mathrm{~mol} \%$ $\mathrm{N}$-acetyl tert-leucine $4 \mathbf{a}, 2.5$ equivalents of $\mathrm{Ag}_{2} \mathrm{CO}_{3}$ and 2 equivalents of benzoquinone in a solution of NMP at $50{ }^{\circ} \mathrm{C}$ for $15 \mathrm{~h}$ to afford $\mathbf{3 a}$ in $81 \%$ yield (Figure $2 \mathrm{~b}$ ). While other amino acid ligands produced acceptable yields of $\mathbf{3 a}$, the reaction with ligand $4 \mathbf{a}$ was superior. Both the Pd(II)-catalyst and benzoquinone were essential to the process and the reaction yield was diminished in the absence of silver(I) salts.

An initial proposal for the reaction mechanism of the tertiary alkylamine-directed $\mathrm{C}\left(\mathrm{sp}^{3}\right)-\mathrm{H}$ arylation begins with coordination of amine 1a to $\mathrm{Pd}(\mathrm{II}) \cdot$ ligand catalyst to form Int-I. Cyclopalladation via ligand-assisted concerted metalation deprotonation affords palladacycle Int-II, which undergoes transmetallation with 2a to Int-III; C( $\left.\mathrm{sp}^{3}\right)$ - 
$\mathrm{C}\left(\mathrm{sp}^{2}\right)$-reductive elimination, possibly facilitated by benzoquinone ${ }^{44}$, generates amine $\mathbf{3 a}$ and $\operatorname{Pd}(0)$, which reforms the catalytically active $\mathrm{Pd}(\mathrm{II}) \bullet$ ligand species upon oxidation with $\mathrm{Ag}(\mathrm{I})$.

a
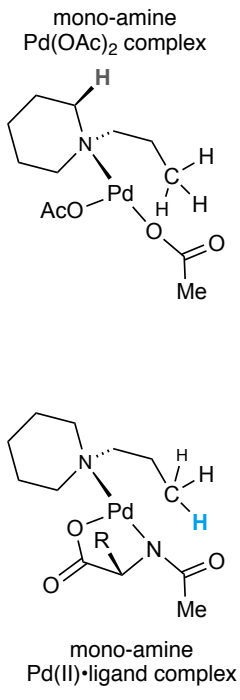

b

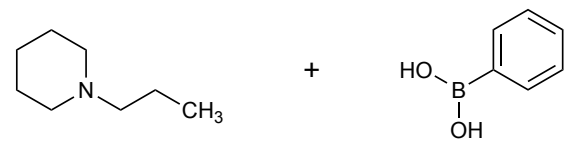

tertiary alkylamine, $\mathbf{1 a}$

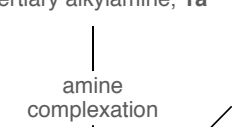

phenylboronic acid, 2a
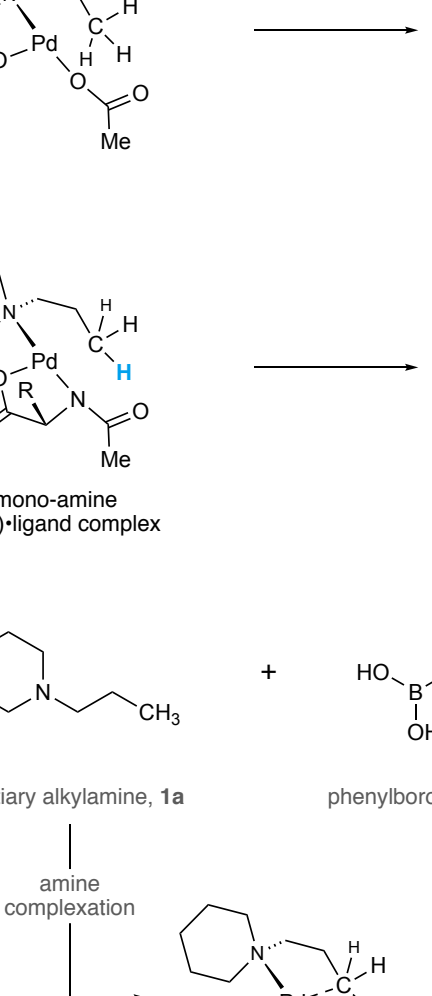

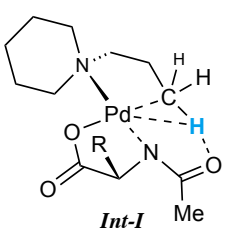

C-H activation

transition state with $\mathrm{Pd}(\mathrm{OAc})_{2} \mathrm{Ts} 1$

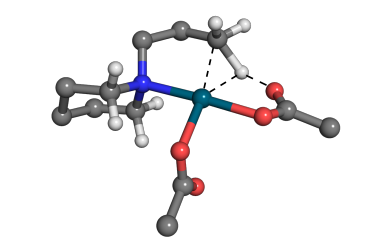

$\mathrm{C}\left(\mathrm{sp}^{3}\right)-\mathrm{H}$ bond cleavage disfavored

transition state with $\mathrm{Pd}(\mathrm{OAc})_{2}$ \& ligand Ts3

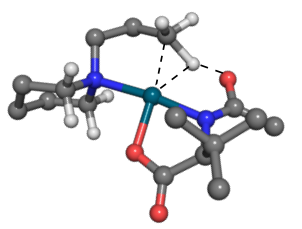

$\mathrm{C}\left(\mathrm{sp}^{3}\right)-\mathrm{H}$ bond cleavage favored
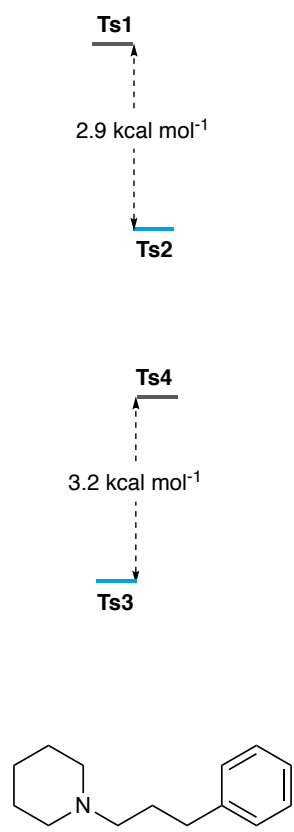

$\gamma$-(hetero)aryl tertiary alkylamine, 3a

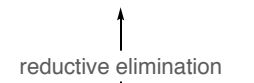

transmetallation

$\mathrm{PhB}(\mathrm{OH})_{2}$
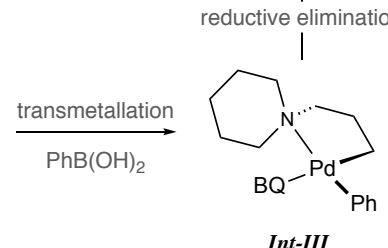

transition state with $\mathrm{Pd}(\mathrm{OAc})_{2}$ Ts2

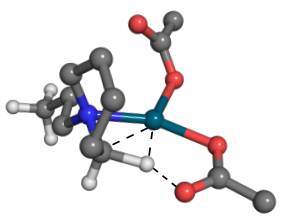

$\beta$-hydride elimination favored transition state with $\mathrm{Pd}(\mathrm{OAc})_{2}$ Ts4

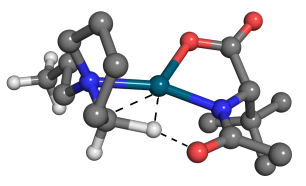

$\beta$-hydride elimination disfavored
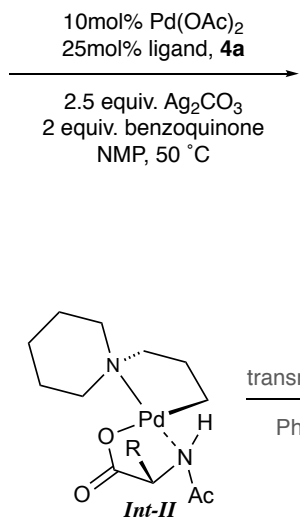

$N$-acetyl $t$-leucine, $4 a$

Figure 2. $\gamma-\mathbf{C}\left(\mathbf{s p}^{3}\right)-\mathbf{H}$ arylation of tertiary alkylamines. a. Computational determination of ligand enabled $\gamma-\mathrm{C}\left(\mathrm{sp}^{3}\right)-$ $\mathrm{H}$ activation. $\gamma-\mathrm{C}-\mathrm{H}$ activation in the ligand-less amino-alkyl $\mathrm{Pd}(\mathrm{II})$ complex was found to require a higher energy transition state (TS1) than for the corresponding $\beta$-hydride elimination (TS2). In contrast, with the amino acid ligand bound to the Pd(II) complex, the corresponding intermediate presented a lower energy transition state (TS3) for ligandassisted $\gamma-\mathrm{C}-\mathrm{H}$ activation in comparison to TS4 (for ligand assisted $\beta$-hydride elimination). Calculations were conducted using B3LYP-D3(BJ)/[G-311+6(2d,p)/SDD(Pd)] IEFPCM(DMF) T=323.15 b. Optimized reaction and proposed mechanism of $\gamma-\mathrm{C}\left(\mathrm{sp}^{3}\right)-\mathrm{H}$ arylations. The $\mathrm{Pd}(\mathrm{OAc})_{2}$, the ligand $\mathbf{4 a}$ and benzoquinone (BQ) are all essential for the observed reactivity. The reaction goes through one turnover in the absence of the $\mathrm{Ag}_{2} \mathrm{CO}_{3}$. While other amino acid ligands also work, 4a gave superior yields. Ligands containing the N-Ac motif were superior to other amide and carbamate derivatives. 
Having established optimal conditions for $\gamma-\mathrm{C}\left(\mathrm{sp}^{3}\right)-\mathrm{H}$ arylation, we next explored the scope of the amine component (Figure 3). $N$-propyl piperidine scaffolds bearing different functionalities on the heterocycle underwent efficient $\mathrm{C}\left(\mathrm{sp}^{3}\right)$ $\mathrm{H}$ arylation to the desired products 3a-m in generally good yields. It was noticeable that the yields of product were slightly reduced in the presence of electron-withdrawing substituents on the heterocycle (3e-f), which may reflect attenuated binding of the amine to the Pd(II)-catalyst brought about by the inductive effect of the remote functionality. Pleasingly, substrates displaying Lewis-basic aromatic heterocycles were compatible with the reaction conditions, delivering $\gamma$-arylated products adorned with functionality commonly found in pharmaceutical and agrochemical intermediates $(\mathbf{3} \mathbf{h}-\mathbf{j})$. The reacting $\mathrm{C}\left(\mathrm{sp}^{3}\right)-\mathrm{H}$ bond can also be located in a 2-ethyl substituent on the piperidine ring, producing amine 3n in useful yield. Interestingly, a substrate with the targeted $\mathrm{C}-\mathrm{H}$ bond in a 3-methyl substituent on the heterocycle undergoes arylation to the 3-benzyl-piperidine derivative 3o. This means that cyclopalladation must have involved the $\mathrm{Pd}(\mathrm{II})$-catalyst binding to the axial lone pair of the piperidine nitrogen, with the reacting methyl group also projected in the axial position. Other saturated heterocycles, including protected piperazines, morpholines and diazepanes were compatible with the $\gamma-\mathrm{C}\left(\mathrm{sp}^{3}\right)-\mathrm{H}$ arylation (3p-s); the lower yield of pyrrolidine $\mathbf{3 t}$ is due to competing $\beta$-hydride elimination. Acyclic scaffolds were also compatible with the arylation process. $N, N$-dimethyl-derived tertiary alkylamines, for example, are one of the most common class of amine feature in pharmaceutical and agrochemical agents and a method to elaborate their structures would represent an attractive transformation. However, these substrates can contain up to eight $\mathrm{C}-\mathrm{H}$ bonds adjacent to nitrogen, which means they are especially prone to $\beta$-hydride elimination on complexation with $\mathrm{Pd}(\mathrm{II})$-salts. Therefore, we were pleased to find that a range of $N, N$-dialkylamine derivatives smoothly reacted to form amines $\mathbf{3} \mathbf{u}-\mathbf{a b}$ in good yield, reinforcing the ligand effect in facilitating $\mathrm{C}\left(\mathrm{sp}^{3}\right)-\mathrm{H}$ activation over $\beta$-hydride elimination. Acyclic tertiary alkylamines displaying a variety of $\alpha$ - and $\beta$-substituents along the reacting alkyl chain also undergo $\gamma-\mathrm{C}\left(\mathrm{sp}^{3}\right)-\mathrm{H}$ arylation $(\mathbf{3 v - y})$ and useful functionality could also be incorporated into the nonreacting alkyl substituents without affecting the success of the reaction (3ac). In a case where two equivalent propyl groups are present, $81 \%$ of the mono-arylated 3aa product is isolated with only trace amounts $(8 \%)$ of the competitive diarylation product observed (not shown).

Next, we evaluated the scope of the aryl-boronic acid coupling partner. Aryl groups with electron-donating and withdrawing substituents at the para- and meta- positions were incorporated with good yields to form the $\gamma$-aryl alkylamine products (3ad-am); unfortunately, ortho-substituted aryl-boronic acids resulted in a lower yield (3an). Palladium-sensitive functionalities such as aryl bromides (3ag-ah) were tolerated under the mild reaction conditions. 
Heteroaryl-boronic acids, such as those containing functionalized pyridines and indoles, were successfully introduced into the tertiary amine framework (3ao-ar), offering opportunities for downstream structure modification.

Table 1. Scope of the $\gamma-\mathrm{C}\left(\mathrm{sp}^{3}\right)-\mathrm{H}$ arylation in tertiary alkylamines.

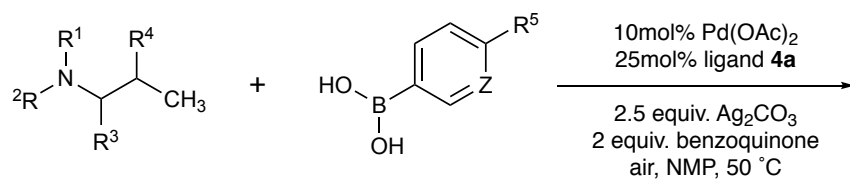<smiles>[R8]c1ccc(CC([R])C([R])N([R])[R])cc1</smiles>

$\gamma$-(hetero)aryl tertiary alkylamine, 3

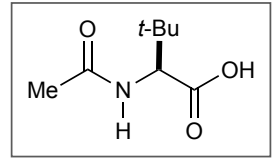

$\mathrm{N}$-acetyl t-leucine $4 \mathrm{a}$

tertiary alkylamine, 1 (2.5 equiv.) (hetero)arylboronic acid, 2<smiles>CCC(C)NC(=O)OCc1ccccc1</smiles>

3g, $78 \%$

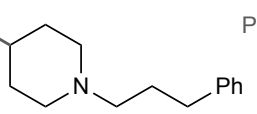

3b, $71 \%$

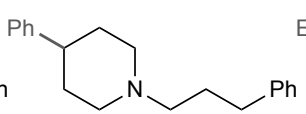

3c, $70 \%$<smiles>CCOC(=O)C1CCN(CCCc2ccccc2)CC1</smiles>

3d, $63 \%$<smiles>FC1(F)CCN(CCCP)CC1</smiles>

$3 e, 46 \%$

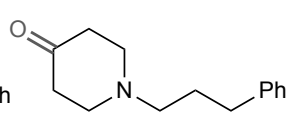

3f, $48 \%$<smiles>Brc1cnn(C2CCN(CCCc3ccccc3)CC2)c1</smiles>

3h, $34 \%$<smiles>N[C@H](c1ncc(Cl)cn1)N(c1ccccc1)[N+](=O)[O-]</smiles>

$3 \mathbf{i}, 60 \%$

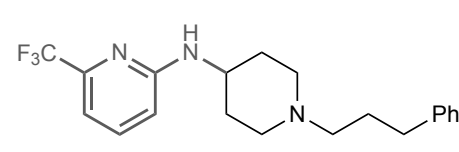

3j, $62 \%$<smiles>COC(Cc1ccccc1)CN1CCCCC1</smiles>

3 k, $53 \%$<smiles>CC(C)(C)OC(=O)N1CCN(CCCc2ccccc2)CC1</smiles>

$3 q, 44 \%$<smiles>CC1CN(CCCc2ccccc2)CC(C)O1</smiles>

$3 r, 51 \%$

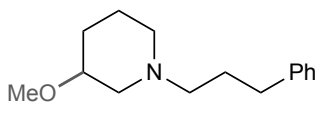

$3 \mathbf{m}, 61 \%$

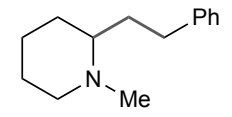

3n, $46 \%$

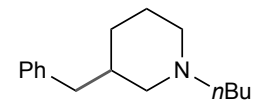

3o, $31 \%$

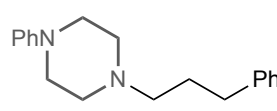

$3 p, 50 \%^{a}$<smiles>COCC(CCc1ccccc1)N(C)C</smiles>

$3 w, 82 \%$<smiles>O=C(c1ccccc1)N1CCCN(CCCc2ccccc2)CC1</smiles>

3s, $45 \%$<smiles>CCOC(=O)C1CCN(CCCc2ccccc2)C1</smiles>

$3 t, 22 \%$<smiles>CN(C)CCCP</smiles>

$3 u, 87 \%$<smiles>CN(C)C(CCP)CCP</smiles>

$3 v, 92 \%$<smiles>CN(C)CC(O)Cc1ccccc1</smiles>

$3 \mathbf{x}, 57 \%$<smiles>CC(=O)C(Cc1ccccc1)CN(C)C</smiles>

$3 y, 40 \%$

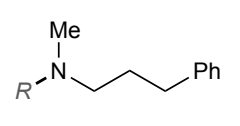

$\mathrm{R}=\mathrm{nBu}, \mathbf{3 z}, 91 \%$ $\mathrm{R}=\mathrm{nPr}, \mathbf{3} \mathbf{a a}, 81 \%$ (8\% diarylation)<smiles>CCN(CC)CCCc1ccccc1</smiles>

$3 a b, 52 \%$

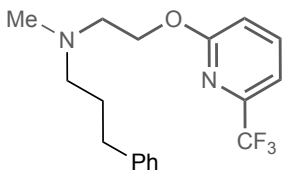

3ac, $65 \%$

(hetero)arylboronic acid scope<smiles>CCOC(=O)c1ccc(CCC(C)N(C)C)cc1</smiles><smiles>COc1cccc(CCC(C)N(C)C(C)CCc2cc(CCC(C)N(C)C)ccc2OC)c1</smiles><smiles>COc1ccccc1CCC(C)N(C)C</smiles>

3an, $29 \%$<smiles>C[C@H](CCc1ccc(C(F)(F)F)nc1)N(C)C</smiles>

3ao, $68 \%$<smiles>C[C@H](CCc1ccnc(Cl)c1)N(C)[N+](=O)[O-]</smiles>

3ap, $66 \%$<smiles></smiles>

a The reaction to produce $3 \mathrm{p}$ was conducted at $60{ }^{\circ} \mathrm{C}$ under conditions otherwise identical to the optimized protocol. 
Fenpropimorph 5, a marketed fungicide, can be synthesized in a single step from readily available materials (1ad and 2p), demonstrating a convergent coupling application to target synthesis (Figure 4a). Such a strategy would be particularly appealing for the synthesis of fenpropimorph analogues, wherein assembly via classical reductive amination or alkylation strategies may be limited by the availability of the corresponding substituted hydrocinnamaldehyde or C33-aryl-1-bromopropanes; readily available N-propyl amines could be directly combined with the vast array of commercial arylboronic acids, providing immediate access to a library of analogues. We found that $N$-propyl analogues of donezepil, ciprofloxacin and fluoxetine underwent $\gamma-\mathrm{C}\left(\mathrm{sp}^{3}\right)-\mathrm{H}$ arylation without affecting the functionality in these molecules. (6-8, Figure 4b). The tricyclic antidepressant trimipramine, which is used to treat major depressive disorders, was also an excellent substrate for the arylation process, affording $\gamma$-(hetero)aryl tertiary alkylamine derivatives 9a-c in excellent yield (Figure 4c); 90\% of the unreacted amine starting material can be recovered, further demonstrating the role of ligand $\mathbf{4 a}$ in controlling the selectivity between potentially competing pathways. The success of this transformation demonstrates the potential of its application as a tool for late-stage functionalization of pharmaceutical agents; many different aryl groups could be transferred to already biologically active molecules, producing previously unexplored candidates that would require multistep syntheses to prepared by traditional means.

Given that the $\gamma-\mathrm{C}\left(\mathrm{sp}^{3}\right)-\mathrm{H}$ arylation process requires the presence of ligand $\mathbf{4 a}$, we questioned whether an enantioselective transformation might be possible when using prochiral $N$-iso-butyl tertiary alkylamines (1ae-ag), thereby generating non-racemic $\beta$-methyl $\gamma$-aryl propylamines that would be difficult to synthesize directly by other methods. Enantioselective desymmetrization of iso-butyl groups is challenging because the catalyst must sterically discriminate between an $\alpha$-hydrogen atom and a relatively small $\alpha$-methyl group. Furthermore, the prochiral center is distant from the chirality in the Pd(II)-catalyst, making enantioselective control more challenging ${ }^{45,46}$. On the basis of computational studies, we noted a distinction between two chair-like transitions states that orient the non-reacting methyl group in either an equatorial (Ts5) or axial position (Ts6); the latter transition state appears to be destabilized by pseudo-1,3-diaxial interactions between the axial $N$-Me and non-reacting methyl group and carries an energetic cost of $2.1 \mathrm{kcal} \mathrm{mol}^{-1}$ (Figure 4d). Under the previously optimal conditions, $\mathbf{1 a d}(\mathrm{R}=\mathrm{Me})$ was converted to 3ar with an enantiomeric excess (ee) of $81 \%$; conducting the reaction in DMF at $40{ }^{\circ} \mathrm{C}$ increased the ee to $90 \%$. Interestingly, comparable enantioselectivity was observed with the $N$-acetyl alanine as ligand $(86 \%$ ee), suggesting that steric parameters, alone, are not responsible for the asymmetric induction. Computational analysis suggested that the $\alpha$ substituent on the ligand projects the amide moiety below the square-plane of the palladium(II)-complex, which relays 
the chiral information to the ligated substrate and controls its conformation. The calculated ee ( $88 \%$ for $4 \mathbf{a}, 83 \%$ for $N$ acetyl alanine) agreed with experimental values. A range of aryl-boronic acids and acyclic tertiary alkylamines exhibited good yields and ee's (3as-aw), showing only minimal erosion of the enantioselectivity compared to the parent reaction. Despite the lower levels of asymmetric induction, it is noteworthy that this enantioselective $\gamma-\mathrm{C}\left(\mathrm{sp}^{3}\right)-\mathrm{H}$ arylation methodology can be used to synthesize the fungicide Fenpropidin (3ax) directly from readily available materials in $49 \%$ yield and with $64 \%$ ee. To the best of our knowledge, the only enantioselective synthesis of this compound has been described requiring six chemical steps; the synthesis of non-racemic substituted-aryl analogues of these fungicides would also be directly accessible through this method (vide supra). ${ }^{47}$ Finally, we also demonstrated that the tertiary alkylamine-directed $\gamma$-arylation process can be applied to methylene $\mathrm{C}-\mathrm{H}$ bonds (Figure 4e). On treatment with the standard conditions, the cyclic dimethylamine derivative $\mathbf{1 0}$ underwent methylene $\mathrm{C}-\mathrm{H}$ arylation to form $\mathbf{1 1}$ in a modest, but encouraging, 34\% yield. Notably, 11 was produced mainly as the trans isomer, reflecting a proposed intermediate (int IV) prior to $\mathrm{C}-\mathrm{H}$ activation that must proceed through to a 5,6-trans fused palladacycle; the e.e. of the arylation was also found to be a promising $64 \%{ }^{48}$ 


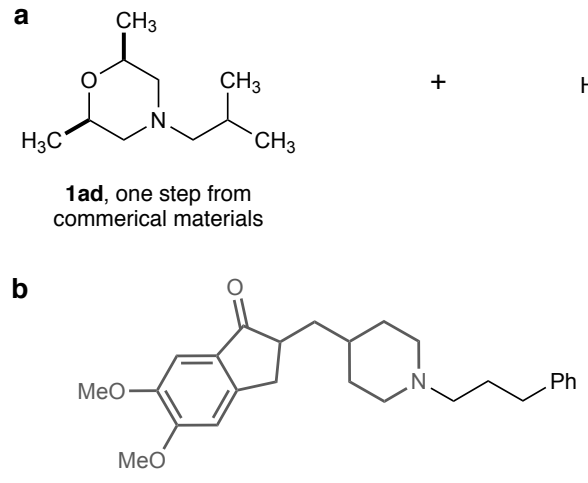

6, $72 \%$, from $N$-propyl-donepezil<smiles>CC(C)(C)c1ccc(B(O)O)cc1</smiles>

$\mathrm{OH}$

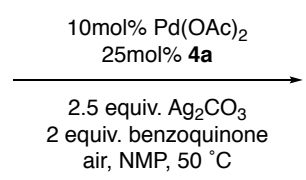

air, NMP, $50{ }^{\circ} \mathrm{C}$<smiles>CC(Cc1ccc(C(C)(C)C)cc1)CN1CC(C)OC(C)C1</smiles>

5

commercial material

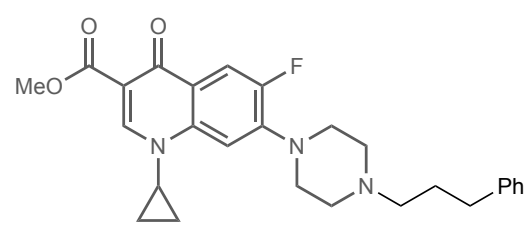

7, 37\%, from N-propyl-Ciprofloxacin<smiles>O=S(=O)(CCCc1ccccc1)N(CCCc1ccccc1)CCC(Oc1ccc(C(F)(F)F)cc1)c1ccccc1</smiles>

8, 96\%, from $N$-propyl-Fluoxetine

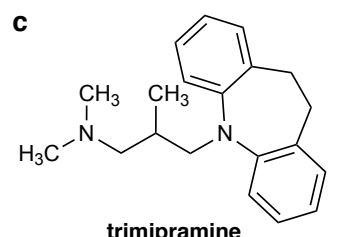

trimipramine

tricyclic antidepressant (Surmontil ${ }^{\mathrm{TM}}$ )

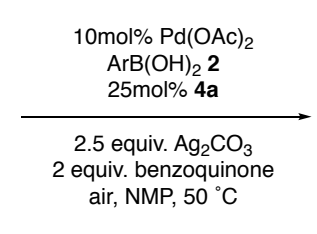

air, NMP, $50^{\circ} \mathrm{C}$

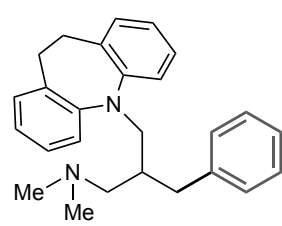

9a, $95 \%$

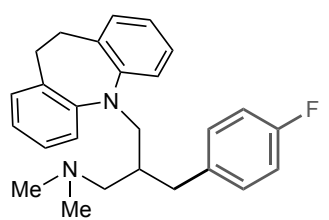

9b, $64 \%$

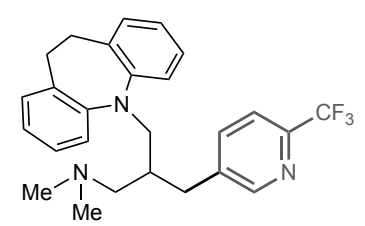

$9 c, 82 \%$

d<smiles>[R]N([R])CC(C)C</smiles>

1ae-ag

enantiotopic methyl groups

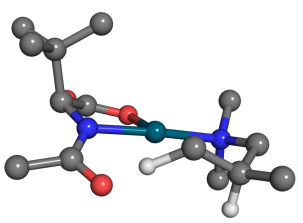

favored transition state Ts

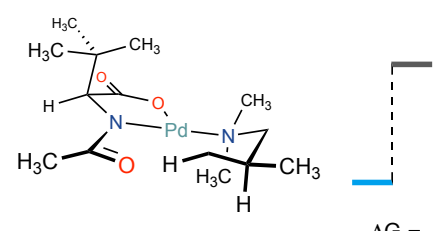

$\Delta \mathrm{G}=$ $\Delta \mathrm{G}=$
$2.1 \mathrm{kcal} \mathrm{mol}^{-1}$

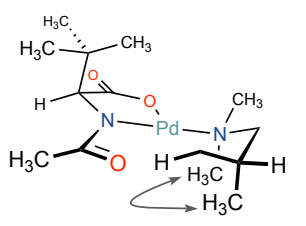

1,3-diaxial interaction

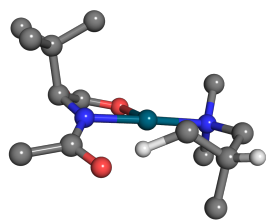

Ts6 disfavored transition state<smiles>[R]c1ccc(CC(C)CN(C)C)cc1</smiles>

3as, $\mathrm{R}=\mathrm{H}, 91 \%$ yield, $90 \%$ ee 3at, $\mathrm{R}=\mathrm{CO}_{2} \mathrm{Et}, 74 \%$ yield, $86 \%$ ee

3au, $76 \%$ yield, $86 \%$ ee

3av, $54 \%$ yield, $82 \%$ ee

3aw, $72 \%$ yield, $82 \%$ ee

3ax, Fenpropidin, $49 \%$ yield, $64 \%$ ee

e<smiles>CN(C)CC1CCOCC1</smiles>

tertiary alkylamine, 10<smiles>OB(O)c1ccccc1</smiles>

phenylboronic acid, $2 \mathbf{a}$

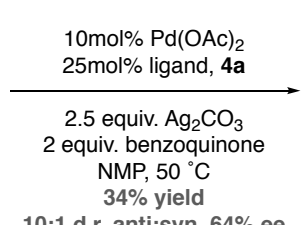

$10: 1$ d.r. anti:syn, $64 \%$ ee

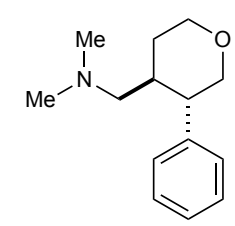

$\gamma$-aryl tertiary alkylamine, 11

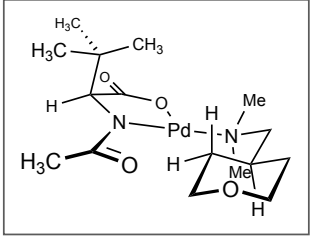

proposed intermediate int IV

Figure 4. Applications and further advances of the $\gamma-\mathbf{C}-\mathbf{H}$ arylation of tertiary alkylamines. a Direct synthesis of the fungicide, Fenpropimorph, from readily available materials. b. $\gamma-\mathrm{C}\left(\mathrm{sp}^{3}\right)-\mathrm{H}$ arylation in substrates containing pharmaceutically relevant amine fragments. c. Late stage arylation of trimipramine. A range of aryl groups can be added directly to trimipramine, generating a range of previously unknown analogues in a single synthetic step d. Enantioselective $\gamma-\mathrm{C}\left(\mathrm{sp}^{3}\right)-\mathrm{H}$ arylation of tertiary alkylamines. Using substrates containing reacting enantiotopic $\gamma$ methyl groups, an enantioselective desymmetrizing arylation generates non-racemic $\beta$-methyl- $\gamma$-aryl tertiary alkylamine products e. Preliminary investigations into methylene $\mathrm{C}-\mathrm{H}$ activation of tertiary alkylamines show selectivity for the trans-isomer on cyclic systems. 
In summary, we have developed a ligand-enabled $\mathrm{Pd}(\mathrm{II})$-catalyzed $\gamma-\mathrm{C}\left(\mathrm{sp}^{3}\right)-\mathrm{H}$ arylation process capable of selectively functionalising a range of tertiary alkylamines with aryl-boronic acids. Not only can the reaction be used to functionalize building block-type amines, synthesize biologically active molecules and applied as a late-stage functionalization tool, but the reaction can be performed enantioselectively.

Acknowledgments: We are grateful to the EPSRC UK National Mass Spectrometry Facility at Swansea University for HRMS analysis. We thank Dr Iacovos Michaelides (AstraZeneca) and Dr Matthew Grayson for useful discussion.

Funding: We are grateful to La Caixa Foundation \& the Cambridge European Trust (J.R.) and the Gates Cambridge Trust (N.J.F.) for scholarships, the EPSRC (EP/N031792/1), the Leverhulme Trust (RPG-2016-370 to M.N.), Mitsubishi (H.A.), H2020 Marie Curie Actions (702462 to M.N. and 656455 to M.E.B.) and the Royal Society for a Wolfson Merit Award (to M.J.G.)

Author Contributions: J.R., M.N. and M.J.G. conceived the project. J.R., M.N., H.A. and M.E.B. designed and performed the synthetic experiments. J.R. and N.J.F. designed and performed the computational studies. J.R., M.N., H.A., N.J.F. and M.J.G. prepared the manuscript.

Competing Interests: The authors declare no competing interests.

Data and Materials: Materials and methods, experimental procedures, useful information, mechanistic studies, optimization studies, ${ }^{1} \mathrm{H}$ NMR spectra, ${ }^{13} \mathrm{C}$ NMR spectra and MS data are available in the Supplementary Materials.

Data availability statement: The data that support the findings of this study are available within the paper and its supplementary information files. Raw data are available from the corresponding author on reasonable request

Correspondence and requests for materials should be addressed to M.J.G. (mjg32@cam.ac.uk).

\section{References}

1. Roughley, S. D. \& Jordan, A. M. The medicinal chemist's toolbox: An analysis of reactions used in the pursuit of drug candidates. J. Med. Chem. 54, 3451-3479 (2011).

2. Cernak, T., Dykstra, K. D., Tyagarajan, S., Vachal, P. \& Krska, S. W. The medicinal chemist's toolbox for late stage functionalization of drug-like molecules. Chem. Soc. Rev. 45, 546-576 (2016).

3. Huang, L., Arndt, M., Gooßen, K., Heydt, H. \& Gooßen, L. J. Late transition metal-catalyzed hydroamination and hydroamidation. Chem. Rev. 115, 2596-2697 (2015). 
4. Musacchio, A. J. et al. Catalytic intermolecular hydroaminations of unactivated olefins with secondary alkyl amines. Science 355, 727-730 (2017).

5. M. T. Pirnot, Y. -M. Wang, S. L. Buchwald Copper Hydride-catalyzed Hydroamination of Alkenes and Alkynes, Angew. Chem. Int. Ed., 2016, 54, 2-12.

6. Perez, F., Oda, S., Geary, L. M. \& Krische, M. J. Ruthenium catalyzed transfer hydrogenation for C-C bond formation: hydrohydroxyalkylation and hydroaminoalkylation via reactant redox pairs. Top. Curr. Chem. 374, 35

7. C. D. Matier, J. Schwaben, J. C. Peters, G. C. Fu. Copper-catalyzed alkylation of aliphatic amines induced by visible light. J. Am. Chem. Soc. 139, 17707-17710 (2017)

8. S. Hanna, J. C. Holder, J. F. Hartwig. A Multicatalytic Approach to the Hydroaminomethylation of $\alpha$-Olefins Angew. Chem. Int. Ed. 58, 3368-3372 (2019).

9. A. Trowbridge, D. Reich, M. J. Gaunt, Multicomponent synthesis of tertiary alkylamines by photocatalytic olefinhydroaminoalkylation. Nature 561, 522-527 (2018).

10. S. -Y. Hsieh, J. W. Bode. Lewis Acid Induced Toggle from Ir(II) to Ir(IV) Pathways in Photocatalytic Reactions: Synthesis of Thiomorpholines and Thiazepanes from Aldehydes and SLAP Reagents. ACS Cent. Sci. 3, 66-72 (2017). 11. Xie, L.-G., Dixon. D.J. Tertiary amine synthesis via reductive coupling of amides with Grignard reagents Chem. Sci. 8, 7492-7497 (2017).

12. G. Grogan. Synthesis of chiral amines using redox biocatalysis. Curr. Opin. Chem. Biol. 43, 15-22 (2018).

13. Ouyang, K., Hao, W., Zhang, W. -X. \& Xi, Z. Transition-metal-catalyzed cleavage of C-N single bonds. Chem. Rev. 115, 12045-12090 (2015).

14. Ghose, A. K., Herbertz, T., Hudkins, R. L., Dorsey, B. D. \& Mallamo, J. P. Knowledge-based central nervous system (CNS) lead selection and lead optimization for CNS drug discovery. ACS Chem. Neurosci. 3, 50-68 (2012).

15. He, J., Wasa, M., Chan, K. S. L., Shao, Q. \& Yu, J. Q. Palladium-catalyzed transformations of alkyl C-H bonds. Chem. Rev. 117, 8754-8786 (2017).

16. Davies, H. M. L. \& Morton, D. Guiding principles for site selective and stereoselective intermolecular C-H functionalization by donor/acceptor rhodium carbenes. Chem. Soc. Rev. 40, 1857-1869 (2011).

17. Capaldo, L. \& Ravelli, D. Hydrogen atom transfer (HAT): A versatile strategy for substrate activation in photocatalyzed organic synthesis. Eur. J. Org. Chem. 2017, 2056-2071 (2017)

18. Giri, R. et al. Palladium-catalyzed methylation and arylation of $\mathrm{sp}^{2}$ and $\mathrm{sp}^{3} \mathrm{C}-\mathrm{H}$ bonds in simple carboxylic acids. J. Am. Chem. Soc. 129, 3510-3511 (2007). 
19. Chen, G. et al. Ligand-enabled $\mathrm{C}-\mathrm{H}$ arylation of amino acids without installing exogenous directing groups.

Angew. Chem. Int. Ed. 56, 1506-1509 (2017).

20. He, C., Whitehurst, W. G. \& Gaunt, M. J. Palladium-catalyzed C( $\left(\mathrm{sp}^{3}\right)-\mathrm{H}$ bond functionalization of aliphatic amines. Chem 5, 1-28 (2019).

21. Lyons, T. W. \& Sanford, M. S. Palladium-catalyzed ligand-directed C-H functionalization reactions. Chem. Rev. 110, 1147-1169 (2010).

22. Rouquet, G. \& Chatani, N. Catalytic functionalization of $\mathrm{C}\left(\mathrm{sp}^{2}\right)-\mathrm{H}$ and $\mathrm{C}\left(\mathrm{sp}^{3}\right)-\mathrm{H}$ bonds by using bidentate directing groups. Angew. Chem. Int. Ed. 52, 11726-11743 (2013).

23. Zaitsev, V. G., Shabashov, D. \& Daugulis, O. Highly regioselective arylation of $\mathrm{sp}^{3} \mathrm{C}-\mathrm{H}$ bonds catalyzed by palladium acetate. J. Am. Chem. Soc. 127, 13154-13155 (2005).

24. He, G. \& Chen, G. A practical strategy for the structural diversification of aliphatic scaffolds through the palladiumcatalyzed picolinamide-directed remote functionalization of unactivated $\mathrm{C}\left(\mathrm{sp}^{3}\right)-\mathrm{H}$ bonds. Angew. Chem. Int. Ed. 50, 5192-5196 (2011).

25. Chan, K. S. L. et al. Ligand-enabled cross-coupling of $\mathrm{C}\left(\mathrm{sp}^{3}\right)-\mathrm{H}$ bonds with arylboron reagents via $\mathrm{Pd}(\mathrm{II}) / \mathrm{Pd}(0)$ catalysis. Nat. Chem. 6, 146-150 (2014).

26. Topczewski, J. J., Cabrera, P. J., Saper, N. I. \& Sanford, M. S. Palladium-catalysed transannular C-H functionalization of alicyclic amines. Nature 531, 220-224 (2016).

27. Wu, Y., Chen, Y. Q., Liu, T., Eastgate, M. D. \& Yu, J.-Q. Pd-catalyzed $\gamma-C\left(\mathrm{sp}^{3}\right)-\mathrm{H}$ arylation of free amines using a transient directing group. J. Am. Chem. Soc. 138, 14554-14557 (2016).

28. Xu, Y., Young, M. C., Wang, C., Magness, D. M. \& Dong, G. Catalytic C(sp $\left.{ }^{3}\right)-H$ arylation of free primary amines with an exo directing group generated in situ. Angew. Chem. Int. Ed. 55, 9084-9087 (2016).

29. Liu, Y. \& Ge, H. Site-selective C-H arylation of primary aliphatic amines enabled by a catalytic transient directing group. Nat. Chem. 9, 26-32 (2017).

30. Kapoor, M., Liu, D. \& Young, M. C. Carbon dioxide-mediated C(sp $\left.{ }^{3}\right)$-H arylation of amine substrates. J. Am. Chem. Soc. 140, 6818-6822 (2018).

31. Lawrence, J. D., Takahashi, M., Bae, C. \& Hartwig, J. F. Regiospecific functionalization of methyl C-H bonds of alkyl groups in reagents with heteroatom functionality. J. Am. Chem. Soc. 126, 15334-15335 (2004).

32. Murphy, J. M., Lawrence, J. D., Kawamura, K., Incarvito, C. \& Hartwig, J. F. Ruthenium-catalyzed regiospecific borylation of methyl C-H bonds. J. Am. Chem. Soc. 128, 13684-13685 (2006). 
33. Li, Q., Liskey, C. W. \& Hartwig, J. F. Regioselective borylation of the C-H bonds in alkylamines and alkyl ethers. Observation and origin of high reactivity of primary $\mathrm{C}-\mathrm{H}$ bonds beta to nitrogen and oxygen. J. Am. Chem. Soc. 136, $8755-8765$ (2014).

34. Lee, M. \& Sanford, M. S. Platinum-catalyzed, terminal-selective $\mathrm{C}\left(\mathrm{sp}^{3}\right)-\mathrm{H}$ oxidation of aliphatic amines. J. Am. Chem. Soc. 137, 12796-12799 (2015).

35. Mack, J. B. C., Gipson, J. D., Du Bois, J. \& Sigman, M. S. Ruthenium-catalyzed C-H hydroxylation in aqueous acid enables selective functionalization of amine derivatives. J. Am. Chem. Soc. 139, 9503-9506 (2017).

36. Howell, J. M., Feng, K., Clark, J. R., Trzepkowski, L. J. \& White, M. C. Remote oxidation of aliphatic C-H bonds in nitrogen-containing molecules. J. Am. Chem. Soc. 137, 14590-14593 (2015).

37. Schultz, D. M. et al. Oxyfunctionalization of the remote $\mathrm{C}-\mathrm{H}$ bonds of aliphatic amines by decatungstate photocatalysis. Angew. Chem. Int. Ed. 56, 15274-15278 (2017).

38. Ryabov, A. D., Sakodinskaya, I. \& Yatsimirsky, A. Kinetics and mechanism of ortho-palladation of ring-substituted N,N-dimethylbenzylamines. J. Chem. Soc., Dalton Trans., 2629-2638 (1985).

39. Nielsen, R. J. \& Goddard III, W. A. Mechanism of the aerobic oxidation of alcohols by palladium complexes of $N$ heterocyclic carbenes. J. Am. Chem. Soc. 128, 9651-9660 (2006).

40. Yang, Y-F., Hong, X., Yu, J-Q., Houk, K. N. Experimental-computational synergy for selective Pd(II)-catalyzed C-H activation of aryl and alkyl groups. Acc. Chem. Res. 50, 2853-2860 (2017).

41. Chan, K.S.L et al. Ligand-enabled cross-coupling of C(sp3)-H bonds with arylboron reagents via $\mathrm{Pd}(\mathrm{II}) / \mathrm{Pd}(0)$ catalysis. Nature Chem. 6, 146 (2014).

42. Haines, B. E., Yu, J. Q. \& Musaev, D. G. Enantioselectivity model for Pd-Catalyzed C-H functionalization mediated by the mono- $N$-protected amino acid (MPAA) family of ligands. ACS Catal. 7, 4344-4354 (2017).

43. Cheng, G.-J. et al. Role of $N$-acyl amino acid ligands in $\mathrm{Pd}(\mathrm{II})$-catalyzed remote $\mathrm{C}-\mathrm{H}$ activation of tethered arenes. J. Am. Chem. Soc. 136, 894-897 (2014).

44. Vasseur, A., Muzart, J. \& Le Bras, J. Ubiquitous benzoquinones, multitalented compounds for palladium-catalyzed oxidative reactions. Eur. J. Org. Chem. 2015, 4053-4069 (2015).

45. Saint-Denis, T. G., Zhu, R-Y., Chen, G., Wu, Q-F. \& Yu, J-Q. Enantioselective C(sp $\left.{ }^{3}\right)-H$ bond activation by chiral transition metal catalysts. Science 359, 747-759 (2018).

46. Wu, Q. F. et al. Formation of -chiral centers by asymmetric $\beta-\mathrm{C}\left(\mathrm{sp}^{3}\right)-\mathrm{H}$ arylation, alkenylation, and alkynylation. Science 355, 499-503 (2017). 
47. S. N. Mlynarski, C. H. Schuster, J. P. Morken Asymmetric synthesis from terminal alkenes by cascades of diboration and cross-coupling. Nature 505, 386-390 (2014).

48. Chen, G. et al. Ligand-accelerated Enantioselective Methylene C(sp3)-H bond activation. Science 353, 1023-1027 (2016). 